\title{
Assessment of Genome Size Variation in Tall and Dwarf Coconut Accessions by Flow Cytometry
}

\author{
Ranjini Tantry Nagesh ${ }^{1 *}$, Niral Vittal ${ }^{1}$ and K.P. Chandran ${ }^{2}$ \\ ${ }^{1}$ Division of Crop Improvement, ${ }^{2}$ Division of Social Sciences, ICAR-Central Plantation Crops \\ Research Institute, Kasaragod, Kerala, India- 671124 \\ *Corresponding author
}

\begin{tabular}{l} 
Ke y w o r d s \\
Genome size, DNA \\
content, Flow \\
cytometry, 2C \\
value, Intra specific \\
variability \\
\hline Article Info \\
\hline $\begin{array}{l}\text { Accepted: } \\
18 \text { July } 2020 \\
\text { Available Online: } \\
10 \text { August } 2020\end{array}$ \\
\hline
\end{tabular}

A B S T R A C T

Nuclear DNA content and genome size variation in 20 phenotypically divergent coconut accessions including 14 tall and 6 dwarfs of different geographical origin were analyzed by flowcytometry. A flow cytometric protocol amenable to the crop was standardized by comparing four buffer compositions, three sample sizes and four incubation periods for isolated nuclei using Pisium sativum cv. Citrad $(2 \mathrm{C}=9.09 \mathrm{pg})$ as an internal reference standard. The study revealed significant differences for 2C DNA content among the accessions ranging from $5.73 \mathrm{pg}$ to $6.25 \mathrm{pg}$, with $8.79 \%$ difference. The mean 2C DNA content of tall accessions has6.07pg/2C and $5.89 \mathrm{pg} / 2 \mathrm{C}$ in dwarfs, corresponding to $1 \mathrm{C}$ genome size of $2968.23 \mathrm{Mb}$ and $2880.21 \mathrm{Mb}$, respectively. Among the accessions, Guam II Tall (6.258 $\mathrm{pg} / 2 \mathrm{C}$ ) had the highest nuclear DNA content whereas Chowghat Orange Dwarf had the lowest $(5.732 \mathrm{pg} / 2 \mathrm{C})$. The results of the present study suggest existence of intra specific variation for genome size in this species, independent of the place of origin of the distinct accessions.

\section{Introduction}

Coconut (Cocos nucifera L.) is a member of the monocotyledonous family Arecaceae $(2 \mathrm{n}=2 \mathrm{x}=32)$, distributed throughout the humid tropics between $20^{\circ} \mathrm{N}-20^{\circ} \mathrm{S}$ latitude (Beccari 1916). At present, coconut is cultivated in 93 countries in an extent of 12.19 million ha. with an annual production of 69.83 million tons of nuts (CDBSTAT2014).Coconut is a monotypic species with no known wild relatives, in spite of this the crop presents considerable diversity in forms. This high level of intraspecific variability is the result of natural evolution and adaption as well as human intervention in the exploitation of the 
species. The major classification of coconut populations are based on the plant habit and breeding behavior, i.e. tall and dwarf types. Tall palms are late to flower, normally cross pollinated and hence, highly heterozygous. In contrast, dwarf palms are early flowering, more homozygous due to high degree of self pollination (Narayana and John, 1949; Menon and Pandali, 1958).

Generally, both types are present across the tropical areas of Indian Ocean Islands, South and South East Asia, Pacific Ocean islands, Central and South America, Atlantic and African regions and show high variability for morphological characters and for other quantitative traits between the populations as well as within the population (Balakrishnan and Namboodiri, 1987; Ratnambal et al., 2005; Arunachalam et al., 2005; Niral et al., 2007).

The nuclear DNA in plant cells is a source for most of the hereditary material and hence, always subjected to comprehensive studies. The total amount of nuclear DNA in the unreplicated reduced nucleus regardless of ploidy of the taxon is referred as genome size and it is expressed as $\mathrm{C}$-value in picograms (1 pg DNA=978bp) (Dolezel et al., 2003).

In plants the knowledge on genome size variation is important in many areas of research ranging from evolutionary studies to genome sequencing and gene cloning projects. In flowering plants, variation for $1 \mathrm{C}$ nuclear DNA content is nearly 2400- fold high ranging from $0.06 \mathrm{pg}$ in Genlisea margaretae to $152.23 \mathrm{pg}$ in the Paris japonica (Ohri 1996). Indeed, variation in genome size has also been well documented between closely related species or within the species even in the absence of the alteration in chromosome number and structure (Greilhuber, 1998, Ohri 1996 and Knight et al., 2005).
Subsequently, it was found that, such difference is predominantly associated with the changes in the repetitive or non coding DNA sequences and found to have influence on many plant morphological and physiological traits (Lavergne et al., 2010). Correspondingly, over the past decade a number of studies correlated variation in economically important traits such as flower size (Meagher et al., 2005), seed mass (Aliyu et al., 2014) and growth rate (Jian et al., 2017) with the relative variation in their DNA content and inferred that selection of breeding materials can be aided by selecting germplasms based on variation in genome size.

Moreover, several workers have also been reported within species correlation between the genome size and ecological variables such as altitude, latitude and temperature (Knight et al., 2005).

With this context, present study is outlined at understanding whether the intraspecific variations observed at the morphological level in tall and dwarf coconuts are reflected by relative variations in their genome size and their possible correlation with the place of origin.

\section{Materials and Methods}

Twenty coconut accessions (Table 1) of which 14 tall and 6 dwarf accessions maintained in the coconut field gene bank at ICAR- CPCRI, Kasaragod, representing four different place of origin were included in the assessment of genome size variation.

\section{Standardization of sample preparation protocol}

Prior to the estimation of genome size in different coconut accessions, sample preparation protocol has been standardized to 
isolate quality nuclear suspension for flow cytometry analysis.

\section{Different buffer systems screened on coconut}

Screened commonly used four buffer compositions on coconut, including Galbraith's buffer (Galbraith et al., 1983), LB01 buffer (Dolezel et al., 1989), Tris $\mathrm{MgCl}_{2}$ buffer (Pfosser et al., 1995) and Woody Plant buffer (Loureiro et al., 2007).

\section{Leaf sample size and incubation period for coconut and internal reference standard}

Three sets of leaf sample sizes $(50,100$ and $150 \mathrm{mg}$ ) from the young leaf tissue of coconut were tested to determine the suitable quantity of leaf sample size required to release sufficient number of nuclei to the isolation buffer. Leaf sample of $50 \mathrm{mg}$ was used for the internal reference sample as reported in the literature (Dolezel et al., 1998). For the analysis, the leaves of Pisium sativum cv. Citrad of known genome size $(2 \mathrm{n}=9.09 \mathrm{pg})$ was used as an internal reference standard (Dolezel and Bartos, 2005). Prepared sample were incubated in four different incubation periods ranging from $0,15,30$ and 60 minutes.

Sample preparation for flow cytometric analysis

Intact nuclei were isolated by chopping the tender leaf tissue of coconut and internal reference standard using a razor blade, approximately for 90 seconds in a petri dish containing $1.5 \mathrm{ml}$ cold isolation buffer supplemented with $1 \%$ PVP-10 in order to reduce the effect of phenolic compounds released from the coconut leaves. Filtered the nuclei suspension through a $50 \mu$ filter to remove larger leaf debris followed by filtration with $20 \mu$ nylon net filter to separate the intact nuclei. To the filtered lysate $2.5 \mu \mathrm{L}$ of $10 \mathrm{mg} / \mathrm{mL}$ of DNAse free RNAse A and Propidium iodide to a final concentration of $50 \mu \mathrm{g} / \mathrm{mL}$ was added and the mixture was then incubated at $4^{\circ} \mathrm{C}$ under dark condition before the analysis.

\section{Experimental design and data collection}

The relative florescence intensities of PIstained nuclei were measured with a BD accuri C6 flow cytometer at laser excitation $488 \mathrm{~nm}$. The treatment factors (isolation buffer, sample size and incubation period) were applied to the leaves of Chowghat Orange Dwarf (COD) coconut accession and the analysis was repeated on three different days. Further, quality of nuclear suspension was determined based on the values of three variables such as coefficient of variation of G0/G1 peak (\%) (a measure of nuclear integrity and variation in DNA staining), background factor (\%) (a measure of a sample quality) and nuclear yield factor (nuclei sec ${ }^{1} \mathrm{mg}^{-1}$ ) (a proportion of nuclei in suspension in respect to the sample size), calculated as follows (Aliyu, 2012).

Background factor $(\mathrm{BF})=$ Total number of particles - Total number of intact nuclei

Total number of particles X 100

Yield factor $(\mathrm{YF})=$ Total number of intact nuclei/ Number of run time $(\mathrm{s})$

Leaf sample size $(\mathrm{mg})$ 
Performed Analysis of Variance (ANOVA) of three nuclei suspension variables using three factor analysis using SPSS Software (Table 2).

Sample preparation and data analysis for the estimation of 2C DNA content in coconut accessions

Intact nuclei were isolated from 20 coconut accessions following the developed sample preparation protocol. For each accession, three individual palms were selected and analysis was carried out in 2 replicated trials. A total of six samples per accession was measured at a low speed and counted about 1500 nuclei per sample using C6 flow plus software. Parameters for data acquisition were kept constant for all samples. The mean florescence units for both coconut and internal reference standard were recorded based on the positions of histogram G0/G1 peaks (non-replicated phase of the cell cycle) to calculate nuclear DNA content by Dolezel et al., 2003.

$2 \mathrm{c}$ value of the coconut sample $=\mathrm{G} 0 / \mathrm{G} 1$ peak value of the coconut/ G0/G1 peak value of the internal reference standard $\mathrm{x}$ genome size of the reference standard $(2 \mathrm{C}=9.09 \mathrm{pg})$

The genome size calculated was expressed in $\mathrm{pg} / 2 \mathrm{C}$ and converted to mega base-pairs $(\mathrm{Mbp})$ by a conversion factor of $1 \mathrm{pg}=978 \mathrm{bp}$ (Dolezel et al., 2003). The values were then summed up and statistically tested using IBM SPSS version 2.0 software.

\section{Results and Discussion}

\section{Standardization of sample preparation protocol for flowcytometry analysis of coconut}

In the present study, four nuclei isolation buffer, three sample size and three incubation periods were compared in order to isolate quality nuclei suspension for the estimation of 2C DNA content in coconut by flow cytometry. The analysis of variance of the three nuclear suspension quality parameters i.e. coefficient of variation of G0/G1 peak (\%), background factor (\%) and nuclear yield factor (nuclei $\mathrm{sec}^{-1} \mathrm{mg}^{-1}$ ), showed significant variation in the performances of the 4 nuclei isolation buffers, 3 leaf sample size and 3 incubation period (Table 2). All combination interactions of these three factors such as buffer x sample size, buffer x incubation time, sample size $\mathrm{x}$ incubation period, buffer $\mathrm{x}$ sample size $x$ incubation time were statistically significant. The CV values of the histogram peaks vary from 3.88 to $9.29 \%$, background factor of the nuclear suspension was between 20.43 to $44.10 \%$.Nuclear yield for the coconut leaf samples ranged from 0.27 to 0.54 nuclei $\mathrm{sec}^{-1} \mathrm{mg}^{-1}$. Among the four buffers tested Galbraith's buffer was found comparatively efficient followed by LB 01 buffer. Leaf tissue of about $100 \mathrm{mg}$ with incubation period for 15 min gave best quality in terms of sufficient nuclei yield (0.54 nuclei $\left.\mathrm{sec}^{-1} \mathrm{mg}^{-1}\right)$, lesser background noise $(20.43 \%)$ and lowest coefficient of variation of histogram of G0/G1 peak (3.88\%). During the sample preparation slight modification was done by adding $1 \%$ PVP-10 and $15 \mu \mathrm{m} \beta$ mercaptoethanol to the chopping buffers in order to reduce the effect of phenolic compounds released from the coconut leaves. This helped the analysis by increasing the sharpness of the peaks, nuclei yield and reduced $\mathrm{CV}$ values.

\section{Estimation of 2C DNA content in coconut accessions}

The $2 \mathrm{C}$ values of coconut accessions varied from $5.73 \mathrm{pg}$ to $6.25 \mathrm{pg}$ with about $8.79 \%$ difference between the smallest and largest values recorded in the accessions under study. Based on the mean DNA content, $1 \mathrm{C}$ genome 
size of coconut accessions was estimated to be $5885.16 \mathrm{Mb}$. The analysis of variance indicated significant difference in DNA content among the coconut accessions as well as between the dwarfs and talls (Table 3). The accessions belong to Pacific Ocean Islands such as Guam II Tall and Fiji Longtongwan
Tall had the highest DNA content of 6.258 $\mathrm{pg} / 2 \mathrm{C}$ or $3.06 \mathrm{~GB} / 1 \mathrm{C}$ and $6.208 \mathrm{pg} / 2 \mathrm{C}$ or 3.03 $\mathrm{GB} / 1 \mathrm{C}$ respectively. Whereas, Chowghat Orange Dwarf native to India had the smallest (5.732pg/2C or $2.802 \mathrm{~GB} / 1 \mathrm{C}$ ) (Table.4) (Fig. $1)$.

Table.1 List of coconut accessions investigated in this study

\begin{tabular}{|l|l|}
\hline \multicolumn{1}{|c|}{ Place of Origin } & \multicolumn{1}{c|}{ Accessions } \\
\hline South Asia & $\begin{array}{l}\text { West Coast Tall; East Coast Tall; Andaman Ordinary Tall; Benaulim Tall; Sri } \\
\text { Lanka Tall; Chowghat Orange Dwarf; Gudanjali Green Dwarf; Sri Lanka Yellow } \\
\text { Dwarf }\end{array}$ \\
\hline South East Asia & $\begin{array}{l}\text { Java Tall; Philippines Ordinary Tall; Nu HimiKupien Tall; Malayan Orange } \\
\text { Dwarf; Malayan Green Dwarf }\end{array}$ \\
\hline Pacific Ocean Islands & Fiji Longtongwan Tall; Fiji Tall; Guam II Tall; New Guinea Orange Dwarf \\
\hline Central \& S. America \& Africa & Jamaica Tall ; Nigerian Tall; Blanchisseuse Tall \\
\hline
\end{tabular}

Table.2 ANOVA for quality nuclear suspension variables of coconut for buffer composition, leaf tissue sample size and incubation time of isolated nuclei

\begin{tabular}{|l|l|l|l|l|}
\hline Source & $\begin{array}{c}\text { Degrees } \\
\text { of } \\
\text { freedom }\end{array}$ & $\begin{array}{c}\text { Back ground } \\
\text { factor }(\mathbf{\%})\end{array}$ & $\begin{array}{c}\text { Coefficient of } \\
\text { variation } \\
(\mathbf{\%})\end{array}$ & $\begin{array}{c}\text { Nuclear Yield factor } \\
\text { (nuclei sec } \mathbf{~ m g}^{-1} \mathbf{)}\end{array}$ \\
\hline Replication & 2 & $5.7761 \mathrm{NS}$ & $0.7372^{*}$ & $0.0006 \mathrm{NS}$ \\
\hline Buffer & 3 & $4351.4867^{*}$ & $264.7182^{*}$ & $0.4839^{*}$ \\
\hline Sample size & 2 & $302.7204^{*}$ & $7.9942^{*}$ & $0.2198^{*}$ \\
\hline Incubation time & 3 & $635.1279^{*}$ & $13.8540^{*}$ & $0.0739^{*}$ \\
\hline Buffer x Sample size & 6 & $7.5412 \mathrm{NS}$ & $0.5408^{*}$ & $0.0174^{*}$ \\
\hline Buffer x Incubation time & 9 & $73.5734^{*}$ & $1.3224^{*}$ & $0.0109^{*}$ \\
\hline Sample size x incubation time & 6 & $57.6787^{*}$ & $2.5381^{*}$ & $0.0035 \mathrm{NS}$ \\
\hline Buffer x Sample size x incubation time & 18 & $13.6539^{*}$ & $1.0026^{*}$ & $0.0046^{*}$ \\
\hline Error & 94 & 5.5609 & 0.2264 & 0.0026 \\
\hline
\end{tabular}

$*$ - Significant at 5\%,NS - Non Significant, p-Value $<0.05$ - Significant at 5\%, p-Value $<0.01$ - Significant at $1 \%$

Table.3 ANOVA of estimated genome size (pg/2C) in coconut accessions

\begin{tabular}{|l|l|l|l|l|l|}
\hline Source & $\begin{array}{l}\text { Degrees of } \\
\text { freedom }\end{array}$ & $\begin{array}{l}\text { Sum of } \\
\text { squares }\end{array}$ & Mean sum of squares & F cal & F Prob \\
\hline Within tall accessions & 13 & 0.513054 & 0.039466 & 11.85 & 6.5161 \\
\hline Within dwarf accessions & 5 & 0.141221 & 0.028244 & 8.48 & 1.5374 \\
\hline $\begin{array}{l}\text { Between Tall and Dwarf } \\
\text { accessions }\end{array}$ & 1 & 0.467004 & 0.467004 & 140.19 & 1.1927 \\
\hline Error & 40 & 0.133252 & 0.003331 & & \\
\hline Total & 59 & 1.254531 & & & \\
\hline
\end{tabular}


Table.4 Absolute DNA content of coconut accessions, estimated by flow cytometry

\begin{tabular}{|l|l|l|l|l|}
\hline \multicolumn{1}{|c|}{ Accessions } & $\begin{array}{l}\text { International } \\
\text { Abbreviation }\end{array}$ & \multicolumn{1}{|c|}{ Place of origin } & $\begin{array}{c}\text { Absolute DNA } \\
\text { content(2C) in pg }\end{array}$ & $\begin{array}{c}\text { Estimated genome } \\
\text { size } \\
\text { (Mbp/haploid set) }\end{array}$ \\
\hline Talls & & & & \\
\hline West Coast Tall & WCT & India & $6.051 \pm 0.039$ & 2958.939 \\
\hline East Coast Tall & ECT & India & $5.978 \pm 0.077$ & 2923.242 \\
\hline Andaman Ordinary Tall & ADOT & India & $6.053 \pm 0.070$ & 2964.807 \\
\hline Benaulim Tall & BENT & India & $6.130 \pm 0.026$ & 2997.57 \\
\hline Java Tall & JVT & Indonesia & $5.872 \pm 0.026$ & 2871.408 \\
\hline Philippines Ordinary Tall & PHOT & Philippines & $5.937 \pm 0.065$ & 2903.193 \\
\hline NuHimiKupien Tall & NHKT & New Caledonia & $6.136 \pm 0.078$ & 3000.504 \\
\hline Fiji Longtongwan Tall & FJLT & Fiji & $6.208 \pm 0.069$ & 3035.712 \\
\hline Fiji Tall & FJT & Fiji & $5.924 \pm 0.050$ & 2896.836 \\
\hline Guam II Tall & GUBT- II & Guam & $6.258 \pm 0.033$ & 3060.162 \\
\hline Jamaica Tall & JMT & Jamaica & $6.108 \pm 0.092$ & 2986.812 \\
\hline Nigerian Tall & NIT & Nigeria & $6.062 \pm 0.045$ & 2964.318 \\
\hline Blanchisseuse Tall & BLIT & Trinidad \&Tabago & $6.138 \pm 0.025$ & 3001.482 \\
\hline Sri Lanka Tall & SLT & Sri Lanka & $6.198 \pm 0.044$ & 3030.822 \\
\hline Dwarfs & & & & \\
\hline Chowghat Orange Dwarf & COD & India & $5.734 \pm 0.018$ & 2803.926 \\
\hline Gudanjali Green Dwarf & GDD & India & $5.890 \pm 0.029$ & 2880.21 \\
\hline Malayan Orange dwarf & MOD & Malaysia & $5.925 \pm 0.031$ & 2897.325 \\
\hline Malayan Green Dwarf & MGD & Malaysia & $5.954 \pm 0.033$ & 2911.506 \\
\hline Sri Lanka Yellow Dwarf & CYD & Sri Lanka & $5.991 \pm 0.011$ & 2929.599 \\
\hline New Guinea Orange Dwarf & NGOD & Papua New Guinea & $5.804 \pm 0.022$ & 2838.156 \\
\hline CD (5\%) & & & 0.095 & \\
\hline
\end{tabular}

Figure.1 Flow cytometry histogram of dwarf coconut accession, Chowghat Orange Dwarf. Peak a. represent the G0/G1 peak of coconut accession, peak b. represents the G0/G1 peak of internal reference standard pea

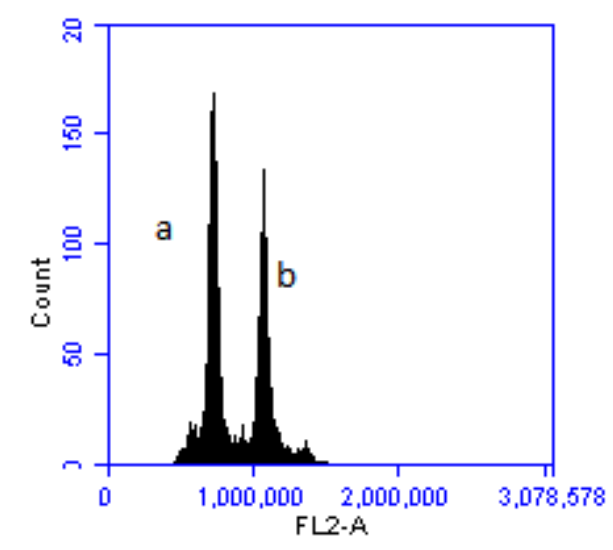

Coconut leaves is known to contain high cytosolic compounds particularly a high level of phenolics and tannins. Such compounds generally interfere with the staining of the isolated nuclei along with the fluorochrome thereby causes errors during the flowcytometry analysis by increasing histogram $\mathrm{CV}$ value and background noise. In 
order to avoid these problems it is advised to modify isolation buffer by adding reducing agents such as PVP and $\beta$-mercaptoethanol which preserve chromatin proteins and counteract the interference of phenolic compounds with DNA staining ((Dolezzel and Barto 2005). Moreover it is also important to test various buffers to identify the best one which is suitable for the crop of our interest because there is no single isolation buffer which works well with all species (Aliyu 2012). Hence, in this investigation, 4 nuclei isolation buffers (Galbraith's buffer, LB01 buffer, Tris $\mathrm{MgCl}_{2}$ buffer and Woody Plant buffer) supplemented with the reducing agents (1\% PVP-10 and15 $\mathrm{m} \mu \beta$-mercaptoethanol) were tested for the preparation of quality nuclei suspension from coconut leaves. Among the 4 buffers tested, Galbraith buffer with PI flurochrome has shown to be most appropriate lysis medium for coconut in order to estimate the relative nuclear DNA because it gave the G0/G1 histogram peak with lesser $\mathrm{CV}$ of $2.90 \%$ and higher nuclei yield of 0.54 (nuclei $\mathrm{sec}^{-1} \mathrm{mg}^{-1}$ ) with least background noise (20.43\%). Galbraith et al., (1998) opinioned that in most cases histograms with peak CVs below 3\% are considered fully acceptable. Lower quality of nuclear suspension was derived from Tris $\mathrm{MgCl}_{2}$ buffer which shows the susceptibility of the buffer to confounding effect of secondary metabolites.

The improved quality of the nuclear suspension extracted using Galbraith buffer over the Tris $\mathrm{MgCl}_{2}$ buffer may be due to the presence of MOPS in the buffer which has a pKa of 7.2 and a better buffering capacity than TRIS with a pKa value of 8.1. Excellent performance of the Galbraith buffer over Tris $\mathrm{MgCl}_{2}$ buffer has also been reported in several plant species (Sedum burrito, Oxalis pes-caprae, Lycopersicon esculentum, Celtis australis, Pisum sativum, Festuca rothmaleri and Vicia faba) (Loureiro et al., 2007).
In addition to the composition of the buffer, size of the leaf sample used for the sample preparation and incubation period of the suspension with flourochrome also influence the quality of the nuclear suspension (Aliyu 2012).In coconut we found that leaf sample size of $100 \mathrm{mg}$ followed by incubation period of 15 minutes was ideal to get quality histogram with lesser background noise compared to higher sample size of $150 \mathrm{mg}$ and incubation period for 60min.This observation had proved the opinion of earlier reporters, more the leaf sample more will be the release of cytosolic compounds to the isolation medium. Similarly, delay the flowcytometric analysis causes rapid degradation of intact nuclei in the suspension and poor quality measurements (Aliyu 2012). The flurochrome propidium iodide (PI) a DNA intercalator is used in the study which is known as best dye and produces histograms with lower variation. Moreover, for the sample preparation choice of proper internal reference standard of known DNA content is important since, it should not overlap with the histogram peaks of the samples under study. Therefore, Pisium sativum cv. Citrad with known genome size of $9.09 \mathrm{pg} / 2 \mathrm{C}$ was selected as an internal standard. Generally nuclear genome of the peas is seem to be stable and ranged from 8.84 to $9.39 \mathrm{pg}$ DNA, which is in the middle of the known range of genome size in plants (Dolezzel and Bartoss, 2005).

Based on the mean DNA content of all the coconut accessions analyzed $1 \mathrm{C}$ genome size was estimated to be $5885.16 \mathrm{Mb}(2 \mathrm{C}$ value is $6.01 \mathrm{pg})$. The $2 \mathrm{C}$ values for 20 coconut accessions are ranged between 5.73 to $6.25 \mathrm{pg}$.The first study on genome size of coconut, estimated using Feulgen densitometry reported mean 2C value of coconut as 7.10pg (Roser et al., 1997). Subsequently, Gunn et al., (2015) recorded mean 1C genome size as $5829.73 \mathrm{Mb}$ based 
on the flow cytometry analysis. Our result is almost concurrent with the Gunn et al., (2015) results even though the authors used different internal reference standard [Pisium sativum $(2 \mathrm{C}=9.09 \mathrm{pg})$ and Petunia xhybrid $(2 \mathrm{C}=2.85 \mathrm{pg})]$ as well as different flurochrome [Propidium iodide and DAPI (4,6- diamidino2-phenylindole, dihydrochloride)] for the analysis.

The inter accession variation for DNA content was about $8.79 \%$ between the largest and smallest values reported. This variation might be the result of addition/deletion of the DNA sequences within the chromosomes. Such differences observed for genome size in coconut accessions correspond to intraspecific variation reported for many plant taxa including maize (Maria et.al. 2015); Sorghum (Laurie D.A. and Bennett M.D., 1985); Coffee (Noirot et al., 2003); Cardamom (Anjali et al., 2016); Tea (Suman et al., 2019)etc.

Further, there is a significant difference for 2C DNA within the tall and dwarf coconut groups. For 14 tall accessions $2 \mathrm{C}$ values ranged between $5.87 \mathrm{pg}$ to $6.25 \mathrm{pg}$, it is about $6.35 \%$ difference; in case of 6 dwarfs it ranges from $5.73 \mathrm{pg} / 2 \mathrm{C}$ to $5.99 \mathrm{pg} / 2 \mathrm{C}$ with only $3.91 \%$ difference. Even though, the values of DNA content in dwarf accessions studied is significantly different, the percentage variation is comparatively less and this indicating more homogeneous nature of the dwarf coconut forms than talls (Narayana and Jhon 1949). Eilam et al., (2007) and Ozkan et al., (2010) inferred that cross pollinated crops possess higher variation for nuclear DNA content compared to self pollinated crops. Even in present study, observed greater variation for $2 \mathrm{C}$ DNA content in allogamous tall coconut accessions than autogamous dwarf accessions.

Some of the researchers reported the presence of a clear geographical gradient in 2C DNA content within the distribution area of the plant species (Knight et al., 2005, Smarda and Bures 2006, Lysak et al., 2009). In Coconut, such distinct differences for nuclear DNA content based on the geographical distribution of accessions was not found, in contrast observed variation for DNA content in the accessions of same place of origin.

Recent advances in genomic research in plant species, successfully correlated the significant differences in genome size, with the economically important traits (Jian et al., 2017) and inferred that in addition to impact of structural genes on quantitative traits, these minor changes in DNA sequences may also have influence on some QTLs in plants. Similarly, in the coconut accessions under study had variation for most of the phenotypic characters including vegetative as well as fruit component traits and which vary significantly for 2C DNA content. Hence, the data furnishing on genome size variation in coconut accessions helps to understand the evolutionary relationship, extend of intraspecific variation and it may pave the way for the crop improvement programme by means of association studies.

\section{Acknowledgement}

Authors highly acknowledges the Laboratory of Molecular Cytogenetics and Cytometry, Institute of Experimental Botany, Czech Republic for providing seeds of Pisium sativum cv. Citrad to use as a reference standard.

\section{References}

Aliyu OM 2012. Development of flow cytometric protocol for ploidy analysis and determination of relative nuclear DNA content in cashew (Anacarium occidentale Linn.). Am. J. Biochem. Mol. Biol. 2: 200-214.

Aliyu OM 2014. Analysis of absolute nuclear 
DNA content reveals a small genome and intra specific variation in cashew (Anacardium occidentale L.) Anacardaceae. Silvae Genet. 63: 285293.

Anjali N, Ganga KM, Nadiya F, Shefeek S and Sabu KK 2016. Intra specific variation in cardamom (Elettaria cardamom Maton): assessment of genomic diversity by flow cytometry, cytological studies and ISSR analysis. SpingerPlus 5: 1-11.

Arunachalam V, Jerard BA, Damodaran V, Ratnamball MJ and Kumaran PM 2005. Phenotypic diversity of foliar traits in coconut germplasm. Genet Resour and Crop Evol 52: 1031-1037.

Balakrishnan PC and Namboodiri KMN 1987. Genetic divergence in coconut. I. Coconut J. 18:13-19.

Beccari, O. 1916. II. Genera Cocos Linn.ele. Palmae affini. Agricotura Colon. 10: 435-471.

CDBSTAT 2014. Coconut Development Board, Statistical Division. (http://coconutboard.nic.in/Statistics.asp $\mathrm{x})$.

Dolezel JP and Bartos J 2005. Plant DNA flow cytometry and estimation of nuclear genome size. Ann. Bot. 95: 99110.

Dolezel JP, Bartos J, Voglmayr $\mathrm{H}$ and Greilhuber J 2003. Nuclear DNA content and genome size of trouts and human. Cytometry 51: 127-128.

Dolezel JP, Binarova P and Lcretti S 1989. Analysis of nuclear DNA content in plant cells by flow cytometry. Biol. Plantarum 31: 113-120.

Eilam T, Anikster Y, Millet E, Manisterski J, Sagi-Assif and Feldman M 2007. Nuclear DNA amount in diploid Triticeae species. Genome 50:10291037.

Galbraith DW, Harkins KR, Maddox JM, Ayres NM, Sharma DP and
Firoozabady E 1983. Rapid flow cytometric analysis of the cell cycle in intact plant tissues. Science 220: 10491051.

Greilhuber J 1998. Intraspecific variation in genome size: a critical reassessment. Ann. Bot. 82: 27-35.

Gunn BF, Baudouin L, Beule T, Ilbert P, Duperray C, Crisp M, Issali A, Konan JL and Rival A 2015. Ploidy and domestication are associated with genome size variation in palms. Am. J. Bot. 102: 1-9.

Jian $\mathrm{Y}, \mathrm{Xu} \mathrm{Ch}$, Guo Z, Wang $\mathrm{S}, \mathrm{Xu} \mathrm{Y}$ and Zou Ch 2017. Maize (Zea mays L) genome size indicated by $180-$ bp knob abundance is associated with flowering time. Sci. Rep. 7: 1-9.

Knight CA, Molinari and Petrov DA 2005.The large genome constraint hypothesis: evolution, ecology and phenotype. Ann. Bot. 95: 177-190.

Laurie D.A. and Bennett M.D. 1985. Nuclear DNA content in the genera Zea and Sorghum. Intergeneric, interspecific and intraspecific variation. Heredity. 55: 307-313.

Lavergne S, Muenke NJ and Molofsky J2010. Genome size reduction can trigger rapid phenotypic evolution in invasive plants. Ann. Bot. 105: 109-116.

Loureiro J, Rodriguez E, Dolezel J and Santos C 2007. Two new isolation buffers for plant DNA Flow cytometry: A test with 37 species. Ann. Bot. 100: 875-888.

Lysak MA, Koch MA, Beaulieu JM, Meister $A$ and Leitch IJ 2009. The dynamic ups and downs of genome size evolution in Brassicaceae. Mol. Bio. Evol.26: 85-98.

Maria F.R., Lidia P., Julian C.H., Graciela E.G. 2015. Intraspecific variation in genome size in maize: cytological and phenotypic correlation. Journal of plant Sciences. 1-12.

Meagher TR, Gillies ACM and Costich DE 2005. Genome size, Quantitative 
Genetics and the Genomic Basis for Flower size Evolution in Silene latifolia. Ann. Bot. 95: 247-254.

Menon KPV and Pandalai KM 1958. The Coconut Palm- A Monograph, Indian Central Coconut Committee Government Press, Madras, India. pp.86-102.

Narayana GV and John CM 1949. Varieties and forms of the coconut. Madras Agric. J. 36:349-36.

Niral V, Geethalakshmi P and Parthasarathy A 2007. Intrapopulation allelomorphism in tall and dwarf populations of the coconut. Acta Bot. Croat. 66:35-42.

Noirot M., Poncet V., Barre P., Hamon P., Hamon S. and De kochko A. 2003. Genome size variation in Diploid African Coffee species. Annals of Botany. 92: 709-714.

Ohri D 1996. Genome size and polyploidy variation in the tropical hardwood genus Terminalia (Combretaceae). Plant Syst. Evol. 200: 225-232.

Ozkan H, Tuna M, Kilian B, Mori N and Ohta S. 2010. Genome size variation in diploid and tetraploid wild wheats. AoB Plants: 1-11.

Pfosser M, Amon A, Lelley T and Heberle B 1995. Evalution of sensitivity of flow cytometry in detecting aneuploidy in wheat using disomic and ditelosomic wheat-rye addition lines. Cytometry, 21: 387-393.

Ratnambal MJ, Muralidharan K, Krishnan M and Amarnath $\mathrm{CH}$ 2005. Diversity of coconut accessions for fruit components. J. Plant. Crops 33: 1-8.

Röser M, Johnson MAT and Hanson L 1997. Nuclear DNA amounts in palms (Arecaceae). Bot. Acta 110: 79-89.

Smarda P and Bures P (2006) Intraspecific DNA content variability in Festuca pallens on different geographical scales and ploidy levels. Ann. Bot. 98: 665678.

Suman S., Sandeep K. and Soom Nath R. 2019. Estimation of nuclear DNA content and its variation among Indian Tea accessions by flowcytometry. Physiol. Mol. Biol. Plants. 25(2): 339346.

\section{How to cite this article:}

Ranjini Tantry Nagesh, Niral Vittal and Chandran, K.P. 2020. Assessment of Genome Size Variation in Tall and Dwarf Coconut Accessions by Flow Cytometry. Int.J.Curr.Microbiol.App.Sci. 9(08): 1611-1620. doi: https://doi.org/10.20546/ijcmas.2020.908.185 